\title{
Texture and strength changes of buried surface-hoar layers with implications for dry snow-slab avalanche release
}

\author{
J. Bruae Jamieson, ${ }^{1}$ Jürg Sahweizer ${ }^{2}$ \\ ${ }^{1}$ Department of Civil Engineering, University of Calgary, Calgary, Alberta T2N 1N4, Canada \\ ${ }^{2}$ Swiss Federal Institute for Snow and Avalanche Research, CH-7260 Davos Dorf, Switzerland
}

\begin{abstract}
Buried layers of surface hoar are the failure plane for many slab avalanches, including fatal human-triggered avalanches in various mountain regions. These layers may persist as weak layers in the snow cover for weeks or months. It is therefore essential for operational avalanche forecasters to monitor the evolution of persistent weak layers, such as buried surface hoar. Traditional grain-shape observations of isolated grains with a magnifier and crystal screen do not show bonding that is decisive for strength. In this study we used in situ microphotography and observations of texture to complement strength measurements from shear frame tests. Buried layers of surface hoar consist of crystals most of which extend from the layer below to the layer above, and may exhibit a columnar or truss-like structure. Observations and measurements show that texture and crystal size change little over periods of up to several months during which the snowpack remains dry. Under these conditions, layer thickness decreases while density and strength increase. Based on field measurements, we argue that the increase in strength is primarily due to penetration of the surface-hoar crystals into the adjacent layers, especially at the bottom of the buried surface-hoar layer, where bonding is critical. The weak bonding at the bottom implies that shear failure occurs at the lower interface rather than within the weak layer. On slopes, we find that surface-hoar crystals that were initially surfacenormal are tilted downslope faster than predicted by published shear strain rates for settled snow, indicating that shear strain is concentrated in these layers. The characteristic texture of buried surface hoar (columnar or truss-like) permits collapsing at the time of fracture. The gravitational energy released by the displacement of the slab may contribute to the extensive fracture propagation associated with buried surface-hoar layers.
\end{abstract}

\section{INTRODUCTION}

When the snow surface is cooled by outgoing longwave radiation to well below the air temperature, surface-hoar crystals may form by deposition of excess water vapour from the near-surface air layer onto the snow surface. As surface-hoar crystals, and ice crystals in general, grow from the vapour phase, their shape and growth rate depend on temperature and degree of supersaturation (Kobayashi, 1961). Planar growth usually produces wedge-shaped crystals (sector plates) or dendritic forms (feathers), which are associated with temperatures of $-10^{\circ}$ to $-21^{\circ} \mathrm{C}$. These can grow in stages forming tiers (Hachikubo and Akitaya, 1997b, 1998) which remain in the same plane (Lang and others, 1984). At temperatures below $-21^{\circ} \mathrm{C}$, most studies of crystal growth in cold laboratories report $c$-axis growth resulting in hollow prisms, columns or sheaths (Kobayashi, 1961). However, Lang and others (1984) describe the surface-hoar crystals in this temperature range as needle-like. As it is difficult to distinguish the various $c$-axis forms in the field, we also refer to these crystals as needle-like crystals.

The most suitable atmospheric conditions for surface-hoar formation usually prevail during clear, cold nights. However, growth is possible during daytime, in shaded areas where the energy balance remains sufficiently negative. As there has to be a certain amount of humidity in the air, clearing in the evening associated with a cold front provides particularly favourable growth conditions. Crystals can grow over several days if the crystals are not destroyed by radiation, wind or rain. Light winds favour surface-hoar formation (Hachikubo and Akitaya, 1997a), presumably since they transport additional water vapour to the snow surface (Colbeck, 1988). Strong winds destroy the temperature inversion near the snow surface. Growth conditions have been studied by Lang and others (1984), Breyfogle (1987), Hachikubo and others (1994) and Hachikubo and Akitaya (1997a, b, 1998). Surfacehoar crystal size varies from the millimetre to the centimetre range. Crystals a few $\mathrm{cm}$ in size (Fig. 1) are quite common, particularly near creeks, where they can grow to $10 \mathrm{~cm}$ or more. Lang and others (1984) observed surface-hoar crystals growing to $50 \mathrm{~mm}$ during two nights, an average growth rate of about $2 \mathrm{~mm} \mathrm{~h}^{-1}$.

Due to their fragile nature, surface-hoar crystals are well known in many mountain regions for forming weak layers once they are buried by subsequent snowfall. In Canada between 1972 and 1991, 34\% of fatal avalanches had failure layers of surface hoar, resulting in 36 fatalities (Jamieson and Johnston, 1992). Conditions are similar in Europe, in particular in the Swiss Alps where Föhn (1993) found that typically $40 \%$ of weak layers in Switzerland contain surface hoar. Avalanche accidents are often clustered shortly after a moderate snowfall buries a surface-hoar layer, as occurred during 14-20 February 1991 when 12 skiers were killed by avalanches in the Swiss Alps. However, buried surface-hoar 


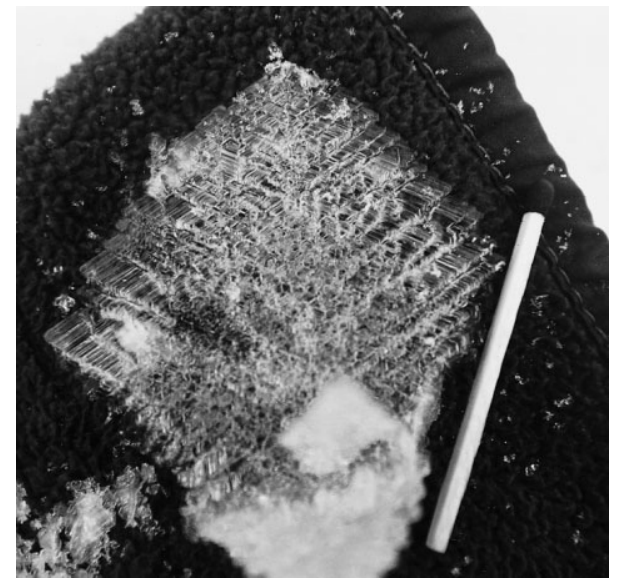

Fig. 1. Surface-hoar crystal ( Bostok Valley, Glacier National Park, British Columbia, Canada, 28 December 1995). Match for scale $(5 \mathrm{~cm})$.

layers may continue to represent a persistent weakness several weeks after a significant snowfall (Jamieson and Johnston, 1994). It is therefore important for operational avalanche forecasters to monitor the evolution of persistent weak layers, such as buried surface hoar (Lang and others, 1984; Schweizer and others, 1998). For a typical skier-triggered slab avalanche, Figure $2 \mathrm{a}-\mathrm{c}$ show the translucent fracture-line profile and surface-hoar crystals in situ and isolated.

Despite the obvious importance for avalanche release, little is known about the evolution of buried surface-hoar layers (Colbeck, 1991). It is extremely difficult to observe and test snow samples that include a surface-hoar layer under controlled conditions in the cold laboratory. However, it is possible to do shear frame measurements in situ and to monitor buried layers over time to follow strength changes (Jamieson and Johnston, 1994). Moreover, without a field method to objectively characterize the buried surface-hoar layers at the time of measurement, it is impossible to relate the observed shear-strength changes to changes in texture.

Recent reviews on snow mechanics emphasize the importance of texture (Shapiro and others, 1997). Obviously, the number, size and type of bonds strongly influence the mechanical properties. Traditional size and shape observations of disaggregated (i.e. isolated) crystals are of limited use in assessing properties related to bonding and strength. The same is true for the technique in which crystals are preserved in iso-octane (Brun and Pahaut, 1991) so they can be characterized later and more objectively in a cold room (Fig. 2b). Plane and serial section techniques (Perla, 1982; Davis and others, 1997) represent an alternative, but require preservation of specimens with pore fillers, transportation of the specimens to a laboratory, and sophisticated laboratory measurements, all of which require more time than is usually available to avalanche forecasters. Three-dimensional reconstruction is possible, but only with high-resolution serial sections. Translucent profiles in the field reveal the snowpack structure (Good and others, 1991) but not the texture within the layer since differences in brightness cannot be related to texture unambiguously.

The aim of this study is to relate changes in texture to changes in strength for buried surface-hoar layers. Fieldworkers usually associate increased rounding and a decreased size of buried surface-hoar crystals over time with an increase in strength. We use microphotography and observations of disaggregated crystals together with shear frame tests to as-
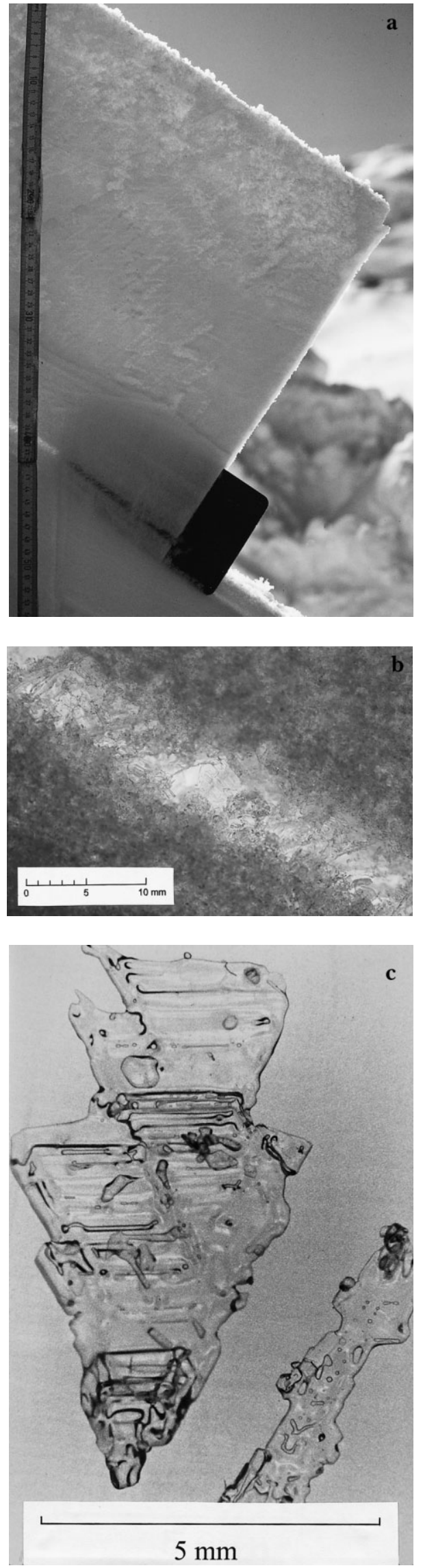

Fig. 2. (a) Translucent profile taken near the crown fracture of a slab avalanche, showing the slab, failure layer of surface hoar and substratum. Height of slab, measured vertically, is $40 \mathrm{~cm}$. (b) In situ close-up photograph of the buried surfacehoar layer from the slab avalanche. (c) Disaggregated crystal from the same layer and preserved in iso-octane (photograph taken in cold laboratory by $G$. Krüsi and C. Fierz of the Swiss Federal Institute for Snow and Avalanche Research). 
sess this assumption. Applying in situ photography of surfacehoar layers in the pit wall provides new insights into the texture of surface-hoar layers. Our observations and measurements should also help in the development of micromechanical models and the assessment of relevant parameters for slab avalanche formation. We propose a conceptual model of surface-hoar texture and its development over time that is consistent with the observations and measured strength changes.

\section{METHODS}

Throughout the winter, we monitored the formation and burial of surface hoar in the field at several study sites in the Columbia Mountains, western Canada. Usually every 4-8 days after burial, we observed a traditional snow profile. At the same time, the thickness of buried surfacehoar layers was measured by placing a scale graduated in $\mathrm{mm}$ against a vertical wall of the snow pit. Surface-hoar crystals and their bonding to adjacent snow layers are observed and photographed using two techniques.

Photographing disaggregated crystals on a black or dark-coloured plate requires that the bonds to neighbouring crystals be broken, but provides the size and shape of disaggregated crystals and changes over time. When extracting surface-hoar crystals from the snowpack and observing their size in the field, we identify a size range that includes the majority of characteristic grains or particles (Colbeck and others, 1990). Sampling during the study was limited, and the length of crystals was observed visually with a $10 \times$ hand lens on a plate, typically with a 1,2 and $3 \mathrm{~mm}$ grid.

To observe the texture of the buried surface-hoar layer we use in situ microphotography. Although we have tried translucent profiles (e.g. Good and Krüsi, 1993) in which a thin wall more or less perpendicular to the Sun is photographed from the shaded side, our usual technique involves pushing a thin black plate into the snow about $1 \mathrm{~cm}$ behind the side-wall of a rectangular pit in the snowpack. We then remove crystals from the weak layer with a knife blade, spatula or pencil point until only two or three unbroken surfacehoar crystals remain at any point between the black plate and the camera. Looking through the camera, we scan the prepared area until a representative group of crystals is found. We use a fixed focal distance, 1:1 magnification and a small aperture (usually f22) to maximize the depth of field. (In winter 1997/98 we used a ring flash to increase the depth of field, shorten the exposure time and thereby obviate the need for a tripod and decrease blurring from falling or blowing snow.) In situ photographs show the thickness of the layer and the orientation and spacing of the crystals (Figs 3 and 4).

We classify the crystals as needle-like, wedges (sector plates), feathers (dendritic forms), cups or composite forms. When the length of most crystals is less than four times the width, as is common for wedges, feathers and cups, we refer to the crystals as a broad form. Many surface-hoar layers are too thin for hardness tests, so we test the strength of the layer with a shear frame (e.g. Roch, 1966; Perla and Beck, 1983; Sommerfeld, 1984). For this test, the bottom of a sheet metal frame is placed a few $\mathrm{mm}$ above the weak layer and manually pulled, parallel to the plane of the layer, with a gauge that records the maximum force. On each test day in our regular study areas we repeat the test 12 times on each persistent weak layer.

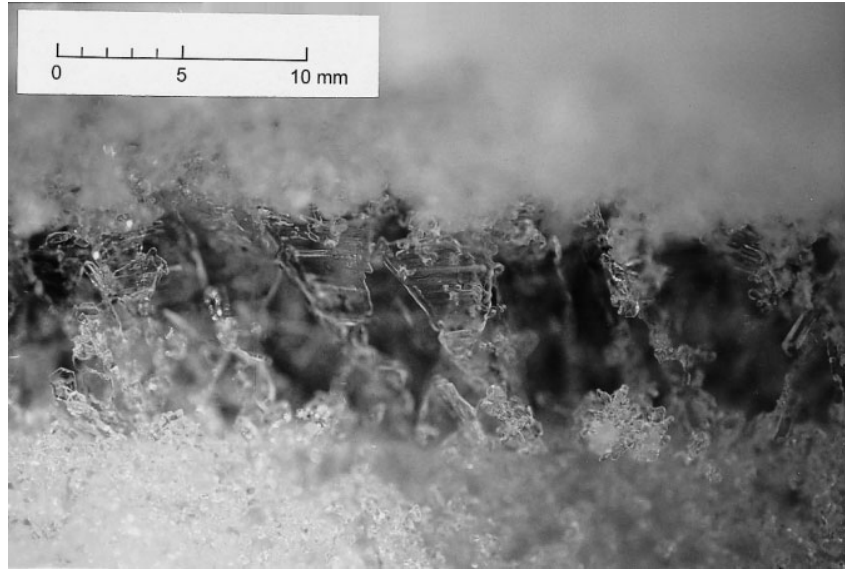

Fig. 3. In situ photograph of surface-hoar layer buried on 15 February 1996 at the Vermont study plot, Purcell Mountains, British Columbia. Photograph taken 26 days after burial. Layer thickness is $8 \mathrm{~mm}$.

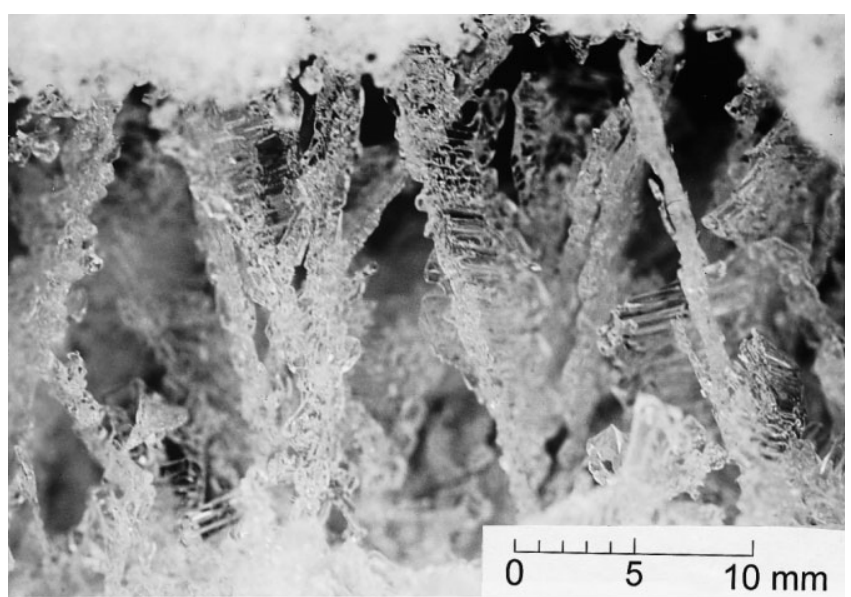

Fig. 4. In situ photograph of surface-hoar layer buried on 11 February 1997 near the Moose Study Slope, Purcell Mountains. Photograph taken 30 days after burial. Layer thickness is $20 \mathrm{~mm}$.

\section{OBSERVATIONS: INITIAL GONDITIONS}

During the three winters of 1995-98, we observed 19 series of changes in surface-hoar layers where each series had a distinct burial date and location (Table 1). We discontinued observations when free water reached the surface-hoar layer or when the temperature of the layer warmed to $0^{\circ} \mathrm{C}$. Each series consisted of 7-15 observations (test days) over burial periods of 33-100 days, showing the remarkable persistence of surface-hoar layers in a dry snowpack. We selected these series for their persistence.

\section{Initial form and texture}

Depending on the micrometeorological conditions, onetwo- or even three-dimensional forms of surface hoar grow. During winters 1995/96 to 1997/98, we observed needle-like forms ( $c$-axis growth), which Lang and others (1985) associate with temperatures below $-21^{\circ} \mathrm{C}$, and two-dimensional forms resembling wedge-shaped plates (sector plates) or feathers (dendritic forms), which are associated with temperatures between $-10^{\circ}$ and $-21^{\circ} \mathrm{C}$ (e.g. Kobayashi, 1961). Occasionally, we also observed cup-shaped crystals, indicative of three-dimensional growth. More often than the complete cups, we observed one main face, with one or two 


\begin{tabular}{|c|c|c|c|c|c|c|c|c|c|c|c|c|c|}
\hline \multirow[t]{2}{*}{$\begin{array}{l}\text { Burial } \\
\text { date }\end{array}$} & \multirow[t]{2}{*}{ Location } & \multirow[t]{2}{*}{ Aspect Slope } & \multirow[t]{2}{*}{ Elevation } & \multirow{2}{*}{$\begin{array}{c}\text { No. } \\
\text { of } \\
\text { test } \\
\text { days }\end{array}$} & \multirow{2}{*}{$\begin{array}{l}\text { Age } \\
\text { when } \\
\text { tested }\end{array}$} & \multicolumn{2}{|c|}{$\begin{array}{l}\text { Minimum size of } \\
\text { crystals }\end{array}$} & \multicolumn{2}{|c|}{$\begin{array}{l}\text { Maximum size of } \\
\text { crystals }\end{array}$} & \multicolumn{2}{|c|}{ Thickness of layer } & \multicolumn{2}{|c|}{ Shear strength of layer } \\
\hline & & & & & & $\begin{array}{l}\text { when } \\
\text { first } \\
\text { tested }\end{array}$ & $\begin{array}{c}\text { Correlation } \\
\text { with age }\end{array}$ & $\begin{array}{l}\text { when } \\
\text { first } \\
\text { tested }\end{array}$ & $\begin{array}{l}\text { Correlation } \\
\text { with age }\end{array}$ & $\begin{array}{l}\text { when } \\
\text { first } \\
\text { tested }\end{array}$ & $\begin{array}{l}\text { Correlation } \\
\text { with age }\end{array}$ & $\begin{array}{l}\text { when Net } \\
\text { first gain } \\
\text { tested }\end{array}$ & $\begin{array}{c}\text { Correlation } \\
\text { with age }\end{array}$ \\
\hline
\end{tabular}

$\mathrm{dd} / \mathrm{mm} / \mathrm{yy}$

$\mathrm{m}$

days $\mathrm{mm} \quad \tau$

$p \quad \mathrm{~mm} \quad \tau$

$p \quad \mathrm{~mm} \quad \tau$

$\begin{array}{llll}p & \mathrm{kPa} & \mathrm{kPa} & \tau\end{array}$

$p$

$\begin{array}{ll}\text { 28/12/95 } & \text { Mount Fidelity } \\ \text { 17/01/97 } & \text { Mount St Anne } \\ \text { 17/01/97 } & \text { Crystaline Creek N. Fork } \\ \text { 17/01/97 } & \text { Vermont Creek } \\ \text { 10/02/97 } & \text { Mount St Anne log cut } \\ \text { 10/02/97 } & \text { Mount St Anne } \\ \text { 11/02/97 } & \text { Moose Study Slope } \\ \text { 11/02/97 } & \text { Crystaline Creek N. Fork } \\ \text { 11/02/97 } & \text { Vermont Creek } \\ \text { 08/12/97 } & \text { Mount St Anne log cut } \\ \text { 08/12/97 } & \text { Mount St Anne } \\ \text { 10/12/97 } & \text { Moose Study Slope } \\ \text { 10/12/97 } & \text { Vermont Creek } \\ \text { 26/12/97 } & \text { Moose Study Slope } \\ \text { 26/12/97 } & \text { Vermont Creek } \\ \text { 02/02/98 } & \text { Mount St Anne } \\ \text { 03/02/98 } & \text { Moose Study Slope } \\ \text { 13/02/98 } & \text { Mount St Anne } \\ \text { 25/02/98 } & \text { Mount St Anne }\end{array}$

$\begin{array}{ccc}- & 0 & 1905 \\ - & 0 & 1900 \\ \mathrm{NE} & 28 & 2100 \\ - & 0 & 1600 \\ \mathrm{E} & 20 & 1600 \\ - & 0 & 1900 \\ \mathrm{NW} & 28 & 1950 \\ \mathrm{NE} & 28 & 2100 \\ - & 0 & 1600 \\ \mathrm{E} & 20 & 1600 \\ - & 0 & 1900 \\ \mathrm{NW} & 20 & 2100 \\ - & 0 & 1600 \\ \mathrm{NW} & 20 & 2100 \\ - & 0 & 1600 \\ - & 0 & 1900 \\ \text { NW } & 20 & 2100 \\ - & 0 & 1900 \\ - & 0 & 1900\end{array}$

$\begin{array}{cc}15 & 11-95 \\ 12 & 0-64 \\ 8 & 5-47 \\ 12 & 2-45 \\ 7 & 10-43 \\ 9 & 4-45 \\ 8 & 7-34 \\ 7 & 6-33 \\ 8 & 5-32 \\ 9 & 8-94 \\ 7 & 10-67 \\ 14 & 23-100 \\ 14 & 12-86 \\ 14 & 7-84 \\ 7 & 4-36 \\ 10 & 11-60 \\ 13 & 6-45 \\ 9 & 5-49 \\ 7 & 9-37\end{array}$

$\begin{array}{cll}\mathbf{- 0 . 7 5} & \mathbf{1 . E}-\mathbf{0 4} & 15 \\ \mathbf{- 0 . 5 2} & \mathbf{0 . 0 1 8} & 6 \\ -0.43 & 0.133 & 8 \\ -0.14 & 0.529 & 12 \\ -0.44 & 0.169 & 10 \\ -0.22 & 0.399 & 9 \\ -0.35 & 0.219 & 15 \\ 0.00 & 1.000 & 9 \\ \mathbf{- 0 . 7 0} & \mathbf{0 . 0 1 5} & 12 \\ \mathbf{- 0 . 7 7} & \mathbf{0 . 0 0 4} & 30 \\ -0.36 & 0.261 & 6 \\ -0.18 & 0.359 & 10 \\ -0.35 & 0.080 & 12 \\ -0.20 & 0.316 & 6 \\ -0.47 & 0.141 & 5 \\ 0.00 & 1.000 & 3 \\ -0.15 & 0.476 & 8 \\ - & - & 6 \\ -0.59 & 0.062 & 7\end{array}$

$\begin{array}{clllllllll}\mathbf{- 0 . 7 0} & \mathbf{3 . E}-\mathbf{0 4} & 15 & \mathbf{- 0 . 7 9} & \mathbf{4 . E}-\mathbf{0 5} & 0.68 & 4.65 & \mathbf{0 . 8 7} & \mathbf{7 . E}-\mathbf{0 6} \\ \mathbf{- 0 . 6 9} & \mathbf{0 . 0 0 2} & 15 & \mathbf{- 0 . 6 4} & \mathbf{0 . 0 0 4} & 0.18 & 5.57 & \mathbf{0 . 9 1} & \mathbf{4 . E}-\mathbf{0 5} \\ -0.43 & 0.133 & 8 & \mathbf{- 0 . 6 7} & \mathbf{0 . 0 2 0} & 0.80 & 2.84 & \mathbf{0 . 7 1} & \mathbf{0 . 0 1 3} \\ \mathbf{- 0 . 5 8} & \mathbf{0 . 0 0 9} & 15 & \mathbf{- 0 . 7 0} & \mathbf{0 . 0 0 2} & 0.27 & 1.66 & \mathbf{0 . 7 0} & \mathbf{0 . 0 0 2} \\ \mathbf{- 0 . 6 9} & \mathbf{0 . 0 3 0} & 12 & \mathbf{- 0 . 7 3} & \mathbf{0 . 0 2 1} & 0.68 & 1.65 & \mathbf{0 . 8 1} & \mathbf{0 . 0 1 1} \\ -0.34 & 0.201 & 5 & \mathbf{- 0 . 5 5} & \mathbf{0 . 0 4 1} & 0.22 & 3.94 & \mathbf{0 . 8 3} & \mathbf{0 . 0 0 2} \\ -0.48 & 0.094 & 20 & \mathbf{- 0 . 6 2} & \mathbf{0 . 0 3 3} & 0.30 & 0.39 & 0.43 & 0.138 \\ 0.12 & 0.713 & 12 & \mathbf{- 0 . 8 2} & \mathbf{0 . 0 0 9} & 0.30 & 1.95 & \mathbf{0 . 8 1} & \mathbf{0 . 0 1 1} \\ -0.23 & 0.423 & 15 & -0.49 & 0.089 & 0.10 & 1.00 & \mathbf{0 . 9 3} & \mathbf{0 . 0 0 1} \\ \mathbf{- 0 . 9 0} & \mathbf{7 . E}-\mathbf{0 4} & 30 & \mathbf{- 0 . 9 6} & \mathbf{3 . E}-\mathbf{0 4} & 0.34 & 5.73 & \mathbf{0 . 9 4} & \mathbf{4 . E}-\mathbf{0 4} \\ \mathbf{- 0 . 7 6} & \mathbf{0 . 0 1 7} & 7 & -0.37 & 0.243 & 0.91 & 5.21 & \mathbf{0 . 9 0} & \mathbf{0 . 0 0 4} \\ \mathbf{- 0 . 4 4} & \mathbf{0 . 0 3 0} & 10 & \mathbf{- 0 . 6 1} & \mathbf{0 . 0 0 2} & 1.15 & 1.61 & \mathbf{0 . 4 9} & \mathbf{0 . 0 1 4} \\ \mathbf{- 0 . 6 3} & \mathbf{0 . 0 0 2} & 15 & -0.32 & 0.111 & 0.77 & 1.68 & \mathbf{0 . 7 1} & \mathbf{4 . E}-\mathbf{0 4} \\ 0.06 & 0.750 & 4 & -0.34 & 0.094 & 0.98 & 2.96 & \mathbf{0 . 8 5} & \mathbf{2 . E}-\mathbf{0 5} \\ -0.41 & 0.194 & 3 & \mathbf{- 0 . 8 7} & \mathbf{0 . 0 0 6} & 0.86 & 1.53 & \mathbf{0 . 8 1} & \mathbf{0 . 0 1 1} \\ -0.16 & 0.532 & 2 & -0.25 & 0.317 & 1.09 & 1.76 & \mathbf{0 . 5 1} & \mathbf{0 . 0 4 0} \\ 0.04 & 0.830 & 4 & \mathbf{- 0 . 5 8} & \mathbf{0 . 0 0 6} & 0.13 & 1.05 & \mathbf{0 . 8 7} & \mathbf{3 . E}-\mathbf{0 5} \\ -0.15 & 0.576 & 3 & \mathbf{- 0 . 8 5} & \mathbf{0 . 0 0 1} & 0.91 & 4.30 & \mathbf{0 . 8 3} & \mathbf{0 . 0 0 2} \\ \mathbf{- 0 . 9 0} & \mathbf{0 . 0 0 5} & 4 & \mathbf{- 0 . 8 7} & \mathbf{0 . 0 0 6} & 0.79 & 2.87 & \mathbf{0 . 9 0} & \mathbf{0 . 0 0 4}\end{array}$

Note: Significant correlations $(p \leq 0.05)$ are marked in bold.

smaller faces forming the sides of an incomplete cup crystal. The dendritic or feather-like forms (Lang and others, 1984; Breyfogle, 1987) that we observed were composed of much smaller (usually $<1 \mathrm{~mm}$ long) plates, cups or incomplete cups. A particular surface-hoar layer may exhibit the characteristics of more than one growth regime prior to burial, resulting in mixed forms (Fig. 5). In our study in the Columbia Mountains, we observed simple wedge-shaped crystals (sector plates) more often than any other form of surface-hoar crystals, both in snowpack profiles and in the failure layers of dry-slab avalanches.

After burial by a subsequent snowfall, a surface-hoar layer consists of crystals most of which extend from the underlying layer (substratum) to the overlying layer (superstratum). Crystals typically have contacts to the superstratum and to the substratum, but fewer contacts to adjacent surface-hoar crystals. When most crystals were oriented normal to the surface, we observed a columnar texture, whereas

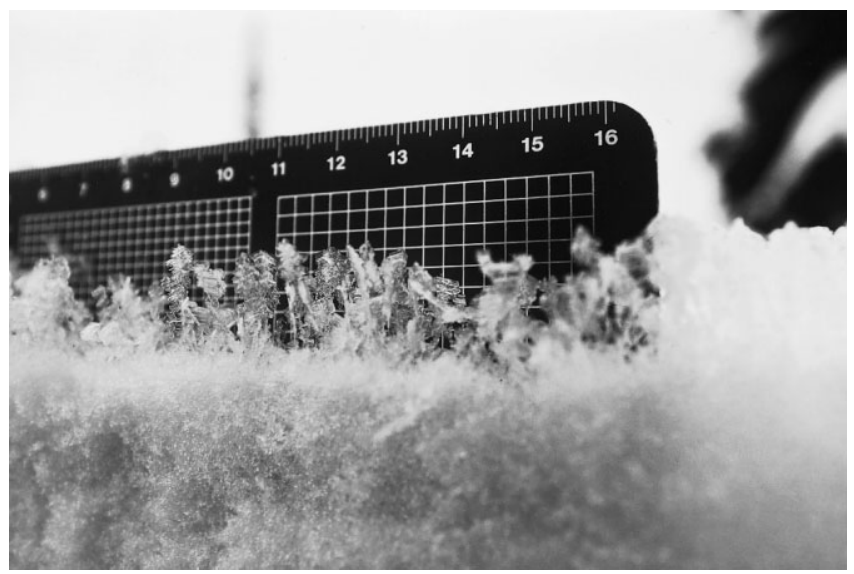

Fig. 5. Surface-hoar crystals on surface near Mount Fidelity, British Columbia. Photograph taken on 28 December 1995 a few hours before burial. Some results of monitoring this layer after burial are shown in Figure 6. when the crystal orientation was more variable, the texture appeared truss-like (discussed below). Lang and others (1984) observed that sector plates and needle-like crystals were usually oriented within a few degrees of surface-normal, whereas dendritic forms such as "feathers" were oriented more randomly but usually within $60^{\circ}$ of surface-normal.

When buried surface-hoar layers were first observed and tested, the minimum size of the disaggregated crystals (column 8 in Table 1) was $2-20 \mathrm{~mm}$ (average $4 \mathrm{~mm}$ ) and the maximum size (column 11 in Table 1) was 3-30 mm (average $10 \mathrm{~mm}$ ). The surface-hoar crystals were much larger than the decomposed and fragmented precipitation particles (typically $1-2 \mathrm{~mm}$ ), rounded grains (typically $0.3-1 \mathrm{~mm}$ ) and faceted crystals (typically $0.5-2 \mathrm{~mm}$ ) found in adjacent layers under dry-snow conditions in the Columbia Mountains.

\section{Thickness and density of layers}

Since most surface-hoar crystals extend from the top to the bottom of the layer, recently buried surface-hoar layers are approximately as thick as the length of the larger crystals. When the buried layers are first observed, the rank correlation between the maximum size of the crystals and the thickness of the layers (columns 11 and 14 in Table 1 ) is $\tau=0.78,\left(p \leq 10^{-5}\right)$, where $\tau$ is the Kendall tau rank correlation and $p$ is the significance level (Neave and Worthington, 1988, p. 177-181). To assess the associations between variables in Table 1, we use rank correlations in preference to the product-moment correlations since some variables are not normally distributed.

Buried surface-hoar layers include many large pore spaces, implying low density. Using point density from plane sections to estimate bulk density, Davis and others (1997) reported densities of approximately $160 \mathrm{~kg} \mathrm{~m}^{-3}$ for two surface-hoar layers buried for 7 and 10 days. Like other fieldworkers, we are unable to measure the density of these 
layers in the field because the layers are too thin for volumetric density samplers.

\section{OBSERVATIONS: CHANGES OVER TIME}

To assess whether crystal size, strength and layer thickness tend to increase or decrease over time, we use a correlation with age (Table 1) in preference to a time-series analysis since the intervals between observations vary from 2 to 15 days (average 6 days).

\section{Shear strength}

The shear strength of the buried surface-hoar layers is correlated with age for the 19 series in Table 1 (rightmost two columns). All the correlation coefficients are positive; 18 of the 19 are significant $(p \leq 0.05)$. The two layers shown in Figures 6 and 7 show a net increase in strength over the winter of about 55 and $25 \mathrm{~Pa} \mathrm{~d}^{-1}$, respectively. These values are typical. Over half of the strength changes reported by Jamieson and Johnston (1998) fall between 0 and $200 \mathrm{~Pa} \mathrm{~d}^{-1}$ over 38 day intervals.

\section{Layer thickness}

Based on plane-section analyses of two series of preserved surface-hoar specimens, Davis and others (1997) showed that the layers thinned as they aged. However, it was unclear if a field measurement of thickness would be accurate enough to show the same trend. During the three winters of 1995-98, we observed the thickness in the field by placing a ruler graduated in $\mathrm{mm}$ against surface-hoar layers in planar vertical walls of snow pits. The measured thickness of the layers is correlated with their age for the 19 series in Table 1.

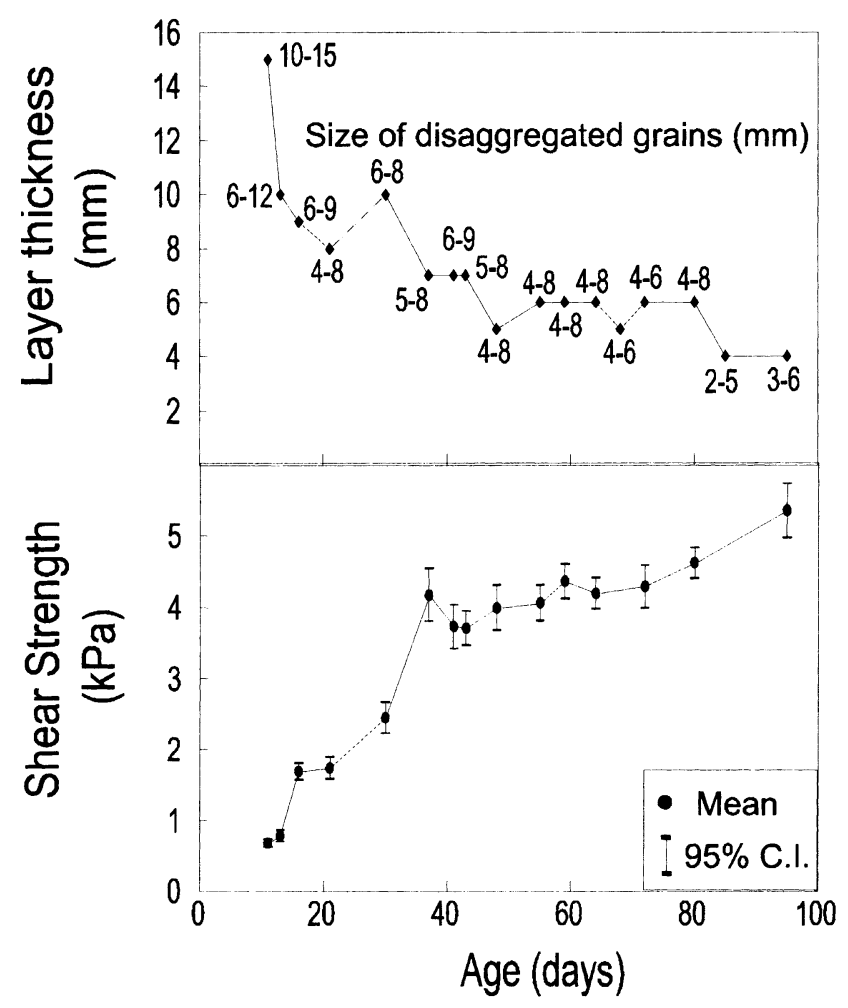

Fig. 6. Time series of shear strength and layer thickness for the surface-hoar layer buried on 28 December 1995 at the Mount Fidelity study plot, 11-95 days after burial. The size range of the disaggregated crystals on each test day is marked on the graph of layer thickness.
All the correlation coefficients are negative, and 14 of the 19 are significant $(p \leq 0.05)$, showing the measured decrease in thickness over time. The decrease in thickness is shown in Figure 6 for the layer buried at the Mount Fidelity study plot on 28 December 1995, and in Figure 7 for the layer buried at the Moose Study Slope on 3 February 1998. The fluctuations in Figure 7 may be due to spatial variability within the study area or to measurement error of $\pm 1-2 \mathrm{~mm}$. Nevertheless, Table 1 and Figures 6 and 7 clearly show that a decrease in thickness of most layers can be measured in the field. The decrease in thickness over a period of 2 months is typically $40-70 \%$.

\section{Crystal size}

To assess the change in size of disaggregated surface-hoar crystals, Table 1 shows the correlation between the age of the layer since burial and the minimum and maximum size. Although most of the correlation coefficients are negative, the decrease in minimum size is only significant $(p \leq 0.05)$ for 4 of the 19 series, and the decrease in maximum size is only significant for 9 of the 19 series. As the layers age, the proportion of large to small disaggregated crystals decreases. So although we observe some decreases in the size of crystals, particularly in the maximum size, the persistence of crystal size under dry snow conditions is noteworthy.

The time series for the Mount Fidelity study plot (Fig. 6) indicates that the grain-size decreased from $10-15 \mathrm{~mm}$ to $3-$ $6 \mathrm{~mm}$ from 11 to 95 days after burial. Except for initially low values on day 6, the time series for the Moose Study Slope (Fig. 7) shows a weaker trend for decreasing grain-size.

\section{Effect of initial crystal size on strength}

Many fieldworkers report that layers of larger surface-hoar crystals are usually slower to gain strength than layers of smaller crystals. To rank the effects of factors such as grainsize, load, temperature of the layer and temperature gradient across the layer, Jamieson and Johnston (1998) used rank

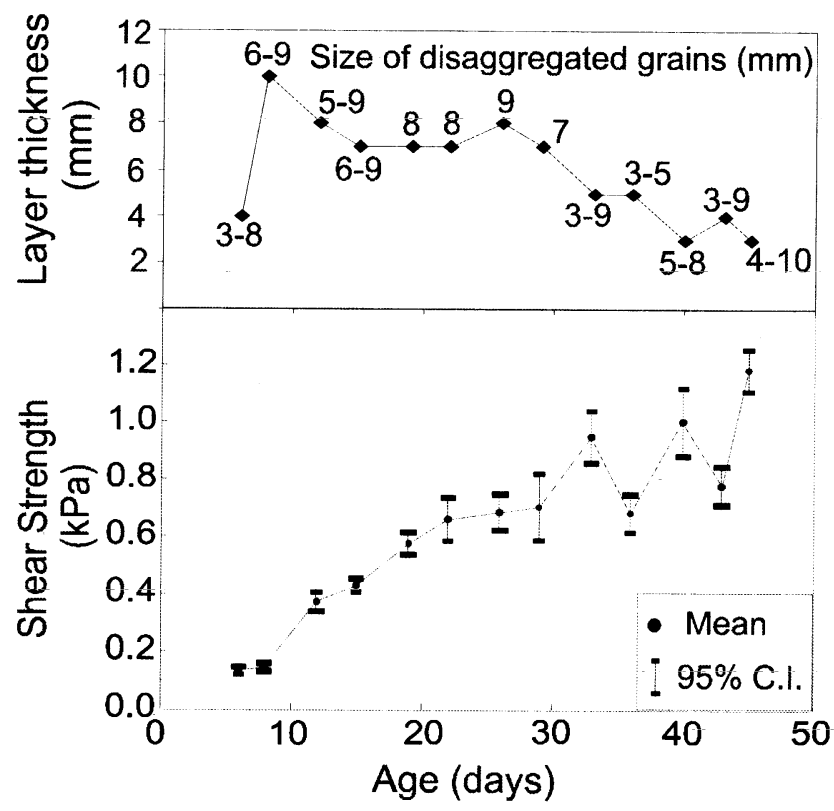

Fig. 7. Time series of shear strength and layer thickness for the surface-hoar layer buried on 3 February 1998 at the Moose Study Slope, 6-45 days after burial. The size range of the disaggregated crystals on each test day is marked on the graph of layer thickness. 
correlations and multivariate regression trees to assess over 300 strength changes of buried surface-hoar layers. They found maximum grain-size to be negatively correlated with the rate of strength change and the second highest ranked factor, which is consistent with the reports of fieldworkers.

\section{Crystal shape}

To observe any change in the shape of buried surface-hoar crystals, we photographed disaggregated crystals at the Moose Study Plot from the layer buried on 10 December 1997 after 21, 42, 67 and 100 days (Fig. 8), during which time the depth increased from 0.35 to $1.21 \mathrm{~m}$, and from the layer buried on 3 February 1998 after 11, 22, 40 and 45 days (Fig. 9), during which time the depth increased from 0.2 to $0.86 \mathrm{~m}$. On the days these layers were observed, the temperature and temperature gradient of the layers averaged $-2.5^{\circ} \mathrm{C}$, $-3.9^{\circ} \mathrm{C} \mathrm{m}^{-1}$ and $-4.3^{\circ} \mathrm{C},-6.1^{\circ} \mathrm{C} \mathrm{m}^{-1}$, respectively, which are in the range associated with equilibrium metamorphism (Colbeck, 1987). These series show that fine striations, sharp edges and sharp corners tended to disappear over time, as expected under these conditions. The disappearance of striations tended to make the crystals more transparent, but this was often obscured by an increase in the number of small grains bonded to the faces of the surface-hoar crystals. One of the 100 day old crystals of the layer buried on 10 December 1997 at the Moose Study Slope showed a glassy appearance (Fig. 8, upper left crystal of lower right photograph). Also, the narrow bases of the wedge-shaped crystals are missing in the advanced stages, presumably because they were broken off during disaggregation.

\section{Orientation of crystals}

Although we do not have any time-series photographs to show the change in orientation of surface-hoar crystals, we

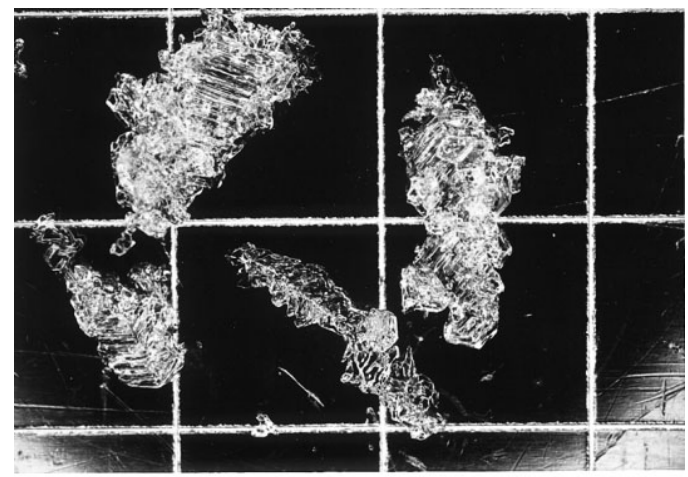

21 days

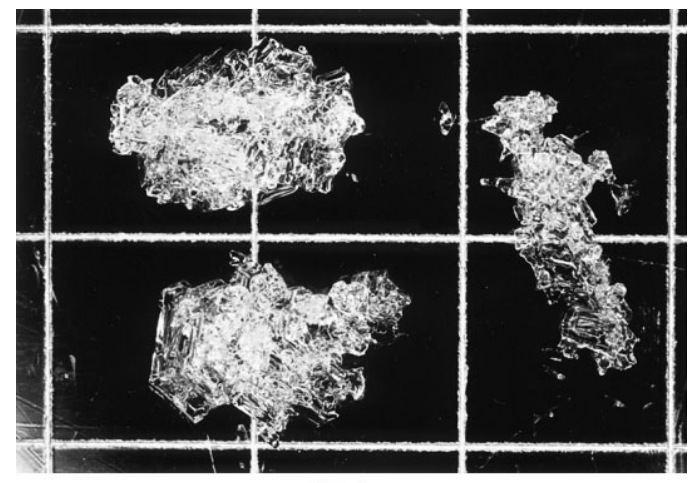

67 days sometimes observed consistent inclination of the crystals on slopes (e.g. Figs 2b and 10). In Figure 10, for example, 30 days after burial a substantial proportion of the crystals was inclined approximately $13^{\circ}$ downslope from surface-normal. Assuming the crystals were initially surface-normal, the shear strain rate averaged $8.8 \times 10^{-8} \mathrm{~s}^{-1}$. This is 4-12 times the shear strain rates for "settled" snow on slopes of $11-30^{\circ}$ (Mellor, 1968, p. 48). This concentration of shear strain in the weak layer is consistent with observations for artificially grown thin layers of depth hoar (Fukuzawa and Narita, 1993). We expect, but cannot prove, that surface-hoar crystals with various orientations from the surface will form a truss-like structure and creep more slowly than uniformly oriented crystals with a columnar structure.

\section{Failure}

We have been testing surface-hoar layers in the Columbia Mountains since winter 1989/90, using mechanical tests such as the shear frame test (Roch, 1966; Sommerfeld, 1984), rutschblock test (Föhn, 1987; Jamieson and Johnston, 1993) and compression test (CAA, 1995; Jamieson and Johnston, 1997). In the last two winters we have made 60 rutschblock tests, 563 compression tests and 2088 shear frame tests in which fracture occurred in surface-hoar layers. We have never observed surface-hoar crystals that remain bonded to the substratum (underlying layer) after fracture, whereas we commonly observe that $10-30 \%$ of the crystals (Fig. 11) remain bonded to the superstratum (overlying layer).

During these winters in the Columbia Mountains, we have also made observations and snow profiles adjacent to 59 dry-slab avalanches that were released by layers of surface hoar. We frequently observed broad surface-hoar crystals - often wedge-shaped plates - in the failure layers, but have no observations of needle-shaped surface hoar in the

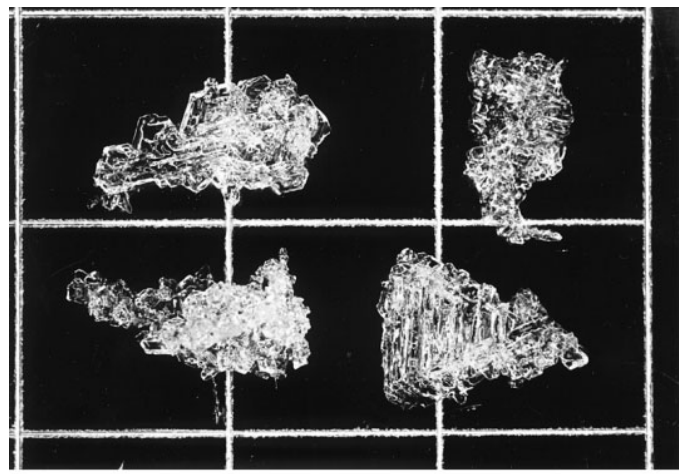

24 days

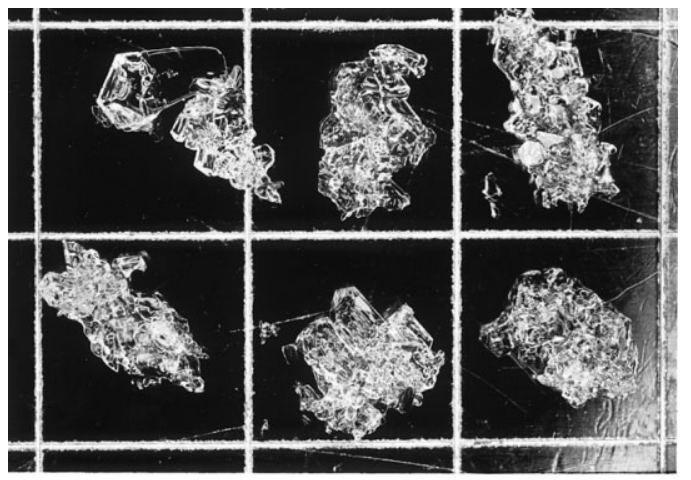

100 days

Fig. 8. Disaggregated surface-hoar crystals at the Moose Study Slope from the layer buried on 10 December 1997 after 21, 42, 67 and 100 days. $10 \mathrm{~mm}$ grid. 


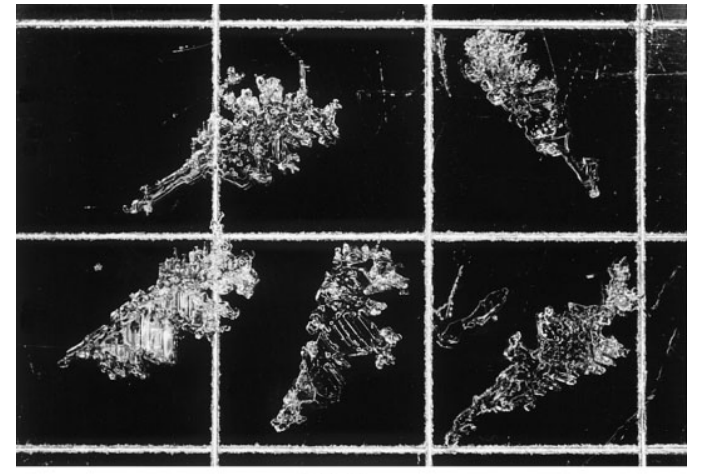

11 days
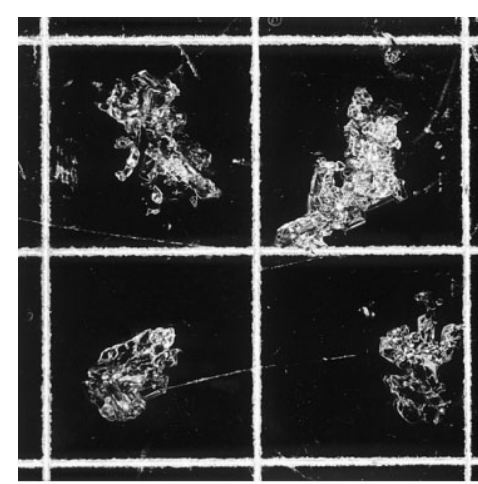

40 days
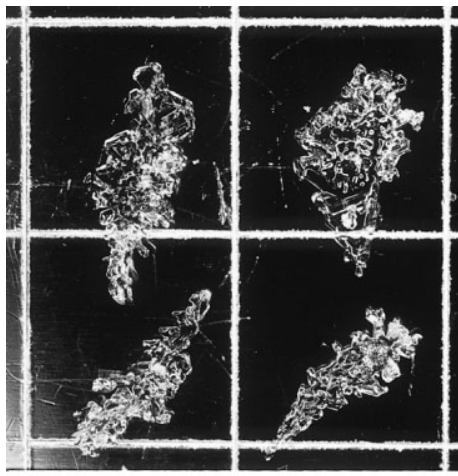

22 days
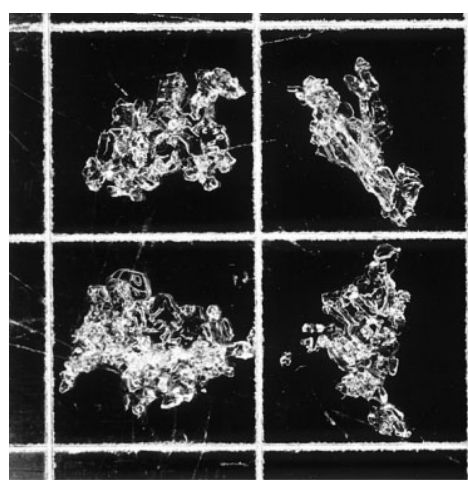

45 days
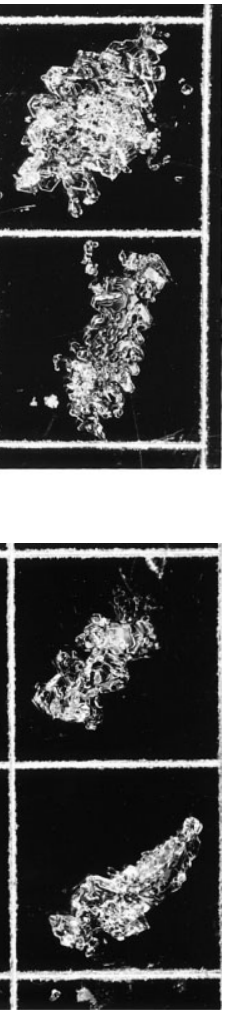

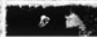

Fig. 9. Disaggregated surface-hoar crystals at the Moose Study Slope from the layer buried on 3 February 1998 after 11, 22, 40 and 45 days. $10 \mathrm{~mm}$ grid.

failure layers. While we have observed layers of needleshaped surface hoar on the surface, we are unsure if these layers may have sublimated on the surface prior to burial or metamorphosed faster than broad forms after burial. Surface-hoar layers consist of relatively large crystals and pore spaces, a texture which is capable of collapsing. Perhaps several hundred times, we have observed collapses while pushing a shear frame into the superstratum and normal to the plane of the surface-hoar layer. This sudden collapse of a surface-hoar layer also occurs when gently placing weights on top of the frame to study normal load dependence (Jamieson, 1995, p. 83-86). Further, we have frequently observed sudden brittle fracture of buried surface-hoar layers in response to a few skiers grouping at the same location, which is often inclined at only $0-20^{\circ}$ (Fig. 12),

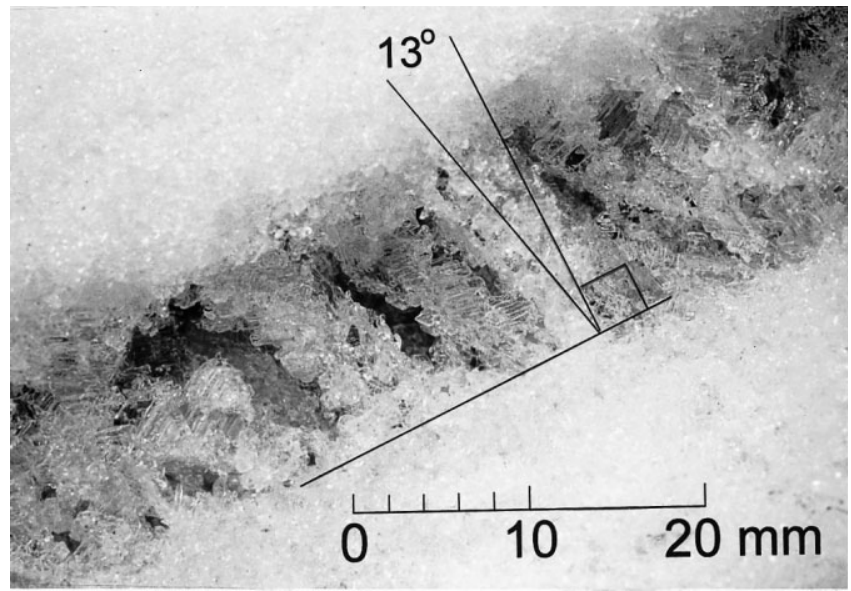

Fig. 10. Buried surface-hoar crystals, 30 days old on a $23^{\circ}$ slope, many of which are tilted approximately $13^{\circ}$ past slopenormal. Layer thickness is approximately $13 \mathrm{~mm}$, measured vertically. or even when walking on skis in flat terrain such as snowcovered lakes. Fractures in which weak snowpack layers suddenly collapse are sometimes accompanied by the wellknown "wum" sound (e.g. Bader and others, 1954, p. 208; Bucher, 1956, p. 71; DenHartog, 1982). This occurs for fractures in surface hoar and for depth hoar. Fractures in buried surface-hoar layers may propagate hundreds of metres across terrain not steep enough to avalanche, before releasing an avalanche on a sufficiently steep slope (Jamieson, 1995, p. 187-188). The gravitational potential energy released by the downward displacement of the slab (Fig. 12) may contribute to the extensive fracture propagation.

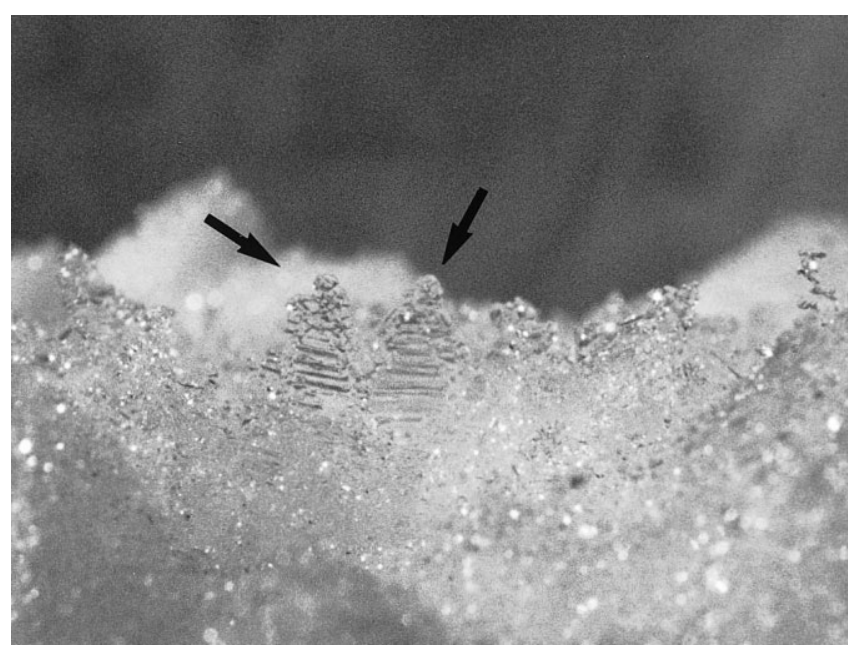

Fig. 11. Surface-hoar crystals (arrow) bonded to part of superstratum gripped by shear frame (turned upside down). Crystal size is $8-10 \mathrm{~mm}$. After fracture by shear frame tests, often 10-30\% of surface-hoar crystals are observed to be bonded to the superstratum, whereas we have not observed that any crystals remain bonded to the substratum. 


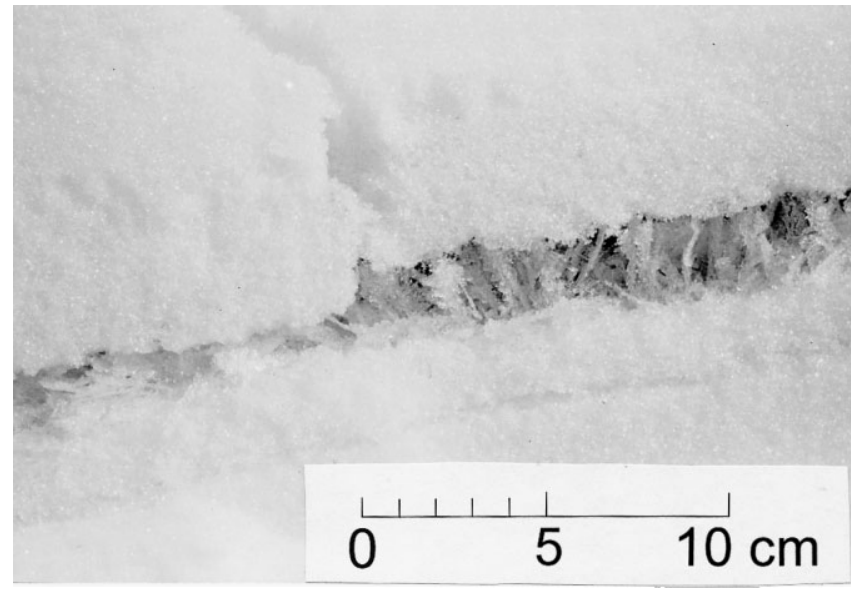

Fig. 12. Fracture in surface-hoar layer triggered by skier $8 \mathrm{~m}$ away, showing vertical and downslope displacement of slab. The slab failed but did not release an avalanche on the $13^{\circ}$ slope. Layer thickness of unfractured surface hoar is approximately $19 \mathrm{~mm}$, measured vertically.

\section{CONGEPTUAL MODEL OF BURIED SURFACE- HOAR TEXTURE AND BONDING}

The common forms of surface hoar are wedge-shaped plates and feathers. These are narrow where they contact the substratum and wider where the next layer will be deposited (Fig. 13a). These broad forms of surface hoar will act as umbrellas preventing many precipitation particles from the next snowfall from reaching the spaces between the surface-hoar crystals (Davis and others, 1997). Crystals inclined at various angles will form more effective umbrellas than crystals with a predominant orientation, such as surfacenormal. These effects create large pore spaces and limit the number of bonds between the surface-hoar layer and the substratum (Fig. 13a). Although there is a similar number of bonds to the superstratum and to the substratum, fracturing along the plane of the layer is more likely at the base than at the top of the surface-hoar layer since contacts to the superstratum, which become bonds over time, are wider than bonds to the substratum. Thus, the strength of surface hoar depends strongly on the bonds at the base of the layer.

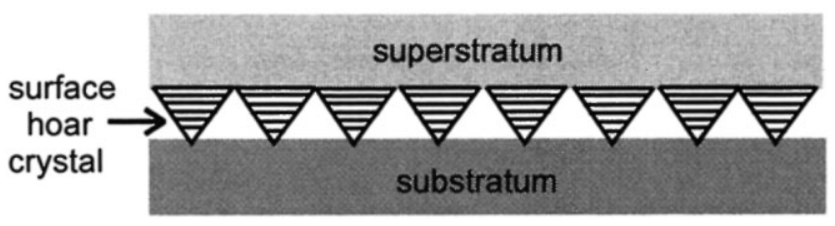

a. soon after burial, little penetration

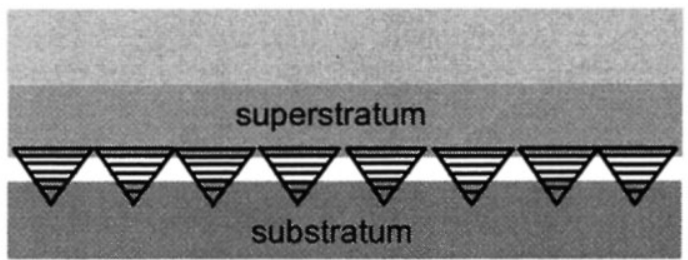

b. weeks after burial, more penetration

Fig. 13. Conceptual model of surface-hoar texture before (a) and after (b) penetration of surface-hoar crystals into superstratum and substratum.
Provided there is no melting, the structure shown schematically in Figure 13a is preserved within the snow cover for weeks or even months, due to the characteristics of dry-snow metamorphism. Since both equilibrium growth (rounding) and kinetic growth (faceting) favour the existence of large crystals at the expense of smaller grains which tend to disappear, the large surface-hoar crystals will retain their size. Bonds between adjacent surface-hoar crystals are limited.

How will the initial texture change over time? Subject to the load and increasing load from overlying layers over a period of days and weeks, the surface-hoar crystals penetrate into the superstratum and substratum (Fig. 13b) where the smaller grains are metamorphosing and rearranging. Wedge- or feather-shaped crystals will concentrate the stress due to the overlying load on their basal contacts. Penetration will therefore be generally more pronounced into the substratum. The surface-hoar layer appears to become thinner, although the large crystals remain the same size. This penetration increases the contact surfaces, enabling additional bonding and a consequent increase in strength. Penetration of the narrow bases of the crystals into the substratum is critical to strength gain. A substratum that is relatively soft and prone to dry metamorphic processes because of high surfaceto-volume ratios, such as precipitation particles or decomposed and fragmented particles, will favour penetration and increased bonding with the surface-hoar layer. Layers, such as crusts, which are hard and slow to metamorphose will resist penetration of the surface-hoar crystals, and the surface-hoar layer will be slow to gain strength. Over time, as bonding due to penetration increases, the layer will become thinner and stronger, and the number of whole surface-hoar crystals that can be extracted (disaggregated) will decrease. Surface-hoar layers that contain many broad crystals at angles other than slope-normal will limit the number of secondary particles that fall into the surface-hoar layer and be slower to gain strength than narrower crystals with more consistent orientation.

\section{DISGUSSION}

\section{Grystal size}

Although the larger surface-hoar crystals are preserved by dry-snow metamorphism, we observed whole crystals less frequently as the buried layer ages (Figs 8 and 9). We attribute this to penetration of the surface-hoar crystals into the substratum and superstratum, and bonding to the grains in these adjacent layers. During disaggregation, surface-hoar crystals will tend to fracture where they have bonded to adjacent layers, resulting in smaller surface-hoar particles over time.

\section{Layer thickness and crystal penetration}

Surface-hoar layers can become thinner over time as a result of crystals being tilted downslope or as a result of crystals penetrating the substratum and superstratum. We rule out a decrease in layer thickness due to a decrease in crystal size since dry-snow metamorphism will tend to preserve the larger surface-hoar crystals. Also, the observed thinning cannot be explained by downslope tilting of the surface-hoar crystals since, for an initially surface-normal crystal, a rotation of $15^{\circ}$ in the first month decreases the height (measured vertically) by only $3 \%$. Further, 7 of the 11 series in Table 1 that were observed at level study plots (where downslope tilting of the 
crystals cannot be a factor) show significant decreases in thickness. So we conclude that penetration of surface-hoar crystals into the substratum and superstratum is the primary mechanism by which surface-hoar layers decrease in thickness over time. In their analyses of the evolution of buried surfacehoar layers, Davis and others (1998) show two examples in which plane sections of surface-hoar layers buried for 3 and 8 days do not show crystals penetrating into the substratum but specimens buried for 60 and 63 days show penetration by some surface-hoar crystals. Penetration will progressively reduce the thickness of surface-hoar layers. Ultimately, penetration will thin surface hoar until bonds form between the superstratum and substratum, at which point the surface-hoar layer will no longer be identifiable.

Other factors being similar, this penetration will require more time for the thicker layers, which will therefore usually gain strength more slowly and be more persistent than thinner layers. This thickness effect coupled with the umbrella effect explains the observation by fieldworkers that layers of larger surface-hoar crystals are usually slower to gain strength than layers of smaller crystals.

\section{Densification}

The densification of surface-hoar layers can be explained by greater penetration of surface-hoar crystals into the substratum than superstratum, which is consistent with the initially smaller contact areas and greater stress concentrations at the base than at the top of the surface-hoar crystals. Density increases with penetration, which is faster in the first few days or weeks and then slows down (due to decreasing stress concentrations as contact areas increase), in contrast to the adjacent layers which usually continue to densify for at least another month (Davis and others, 1997). Other factors which may contribute to the densification of surface-hoar layers include: bonding of grains from the substratum or superstratum onto the surface-hoar crystals; sublimation of water vapour into the concavities at the growth steps on the surface-hoar crystals (consistent with increased transparency); and, to a lesser degree, downslope tilting of the surface-hoar crystals.

\section{Bonding and strength}

The strength of a surface-hoar layer can increase by forming new bonds or by bond growth. Since surface-hoar crystals can penetrate on the order of $\mathrm{mm}$, and crystals in adjacent layers are typically $0.3-1 \mathrm{~mm}$ in size, each surface-hoar crystal can form a number of new contacts. Where equilibrium conditions dominate, as in our study area, new contacts will sinter and form new bonds, increasing the strength of the layer. Using plane sections to monitor changes in four surface-hoar layers, Davis and others (1998) report that the number of bonds counted (subjectively) along the base of the surface-hoar layers increased by $48 \%$ to $100 \%$ over periods of $28-60$ days. Since surfacehoar layers are quite consistently observed to fracture at the interface with the substratum (Fig. 11), their basal bonds are assumed to be critical to their strength in accordance with the conceptual model.

\section{GONGLUSIONS}

Buried surface-hoar layers can be observed for periods of up to 100 days in a dry snowpack. In a dry snowpack, large crystals tend to retain their size and shape. In the Columbia Mountains where equilibrium metamorphism is usually dominant, most surface-hoar layers increase in shear strength and decrease in thickness over periods of several weeks. Both effects are substantial and can easily be measured.

Surface-hoar layers consisting of larger, broader crystals tend to be slower to gain strength, other factors being equal. Consequently, larger, broader crystals of surface hoar are more likely to form the failure layers of slab avalanches than smaller crystals. The bonds at the base of a layer of surfacehoar crystals are critical to the strength of the layer.

Observations on buried surface-hoar layers suggest that penetration of surface-hoar crystals into the adjacent layers is the key mechanism for explaining changes in texture and strength over time. Due to penetration, new contacts are formed with grains in the adjacent layers. The process is most pronounced during loading shortly after burial. Accordingly, the decrease in thickness and the increase in strength and density slows over time.

Summing up, the conceptual model provides a logical and unified explanation of:

(1) the strength gain of surface-hoar crystals associated with thinning of the layer;

(2) the tendency for the proportion of whole disaggregated crystals to decrease over time;

(3) the weak tendency for maximum size of disaggregated surface-hoar particles to decrease over time;

(4) the decreasing rate of densification over time;

(5) reports by fieldworkers that surface-hoar layers containing larger crystals are more persistent than layers of smaller crystals;

(6) the preservation of surface-hoar crystals independent of the temperature gradient; and

(7) the persistence of the surface-hoar layers consisting of broad forms.

Further, it offers one explanation for the abundance of broad surface-hoar forms found in the failure layers of slab avalanches.

As indications of strengthening of buried surface-hoar layers, fieldworkers can monitor thinning of the layer, conglomeration of small particles onto surface-hoar crystals and a decrease in the size of surface-hoar grains, particularly in the maximum grain-size. More time-consuming measurements such as the shear frame test are also suitable for some applications. On low-angled and level terrain, the texture of buried surface hoar is prone to collapsing which may release gravitational potential energy for fracture propagation.

\section{ACKNOWLEDGEMENTS}

We thank S. Colbeck and R. Davis for stimulating discussions on surface hoar and bonding, two anonymous reviewers and the scientific editor, J. Johnson, for constructive comments on an earlier version of the manuscript, C. Johnston for directing the field studies, T. Geldsetzer for advice on photography and for reviewing the photomicrographs, as well as J. Hughes, A. Wilson, S. Lovenuik, N. Irving, G. McAuley, T. Geldsetzer, J. Filippone and K. Black for their careful fieldwork. This study is part of a Collaborative Research and Development Pro- 
ject funded by the British Columbia Helicopter and Snowcat Skiing Operators Association and by the Natural Sciences and Engineering Research Council of Canada.

\section{REFERENCES}

Bader, H., R. Haefeli, E. Bucher, J. Neher, O. Eckel and C. Thams. 1954 Snow and its metamorphism [Der Schnee und seine Metamorphose]. SIPRE Transl. 14.

Breyfogle, S. R. 1987. Growth characteristics of hoarfrost with respect to avalanche occurrence. In ISSW'86. A merging of theory and practice. International Snow Science Workshop, 22-25 October 1986, Lake Tahoe, California. Proceedings. Homewood, CA, ISSW Workshop Committee, 216-222.

Brun, E. and E. Pahaut. 1991. An efficient method for a delayed and accurate characterization of snow grains from natural snowpacks. F. Glaciol., 37(127), 420-422

Bucher, E. 1956. Contribution to the theoretical foundations of avalanche defense construction [Beitrag zu den theoretischen Grundlagen des Lawinenverbaus]. SIPRE Transl. 18.

Canadian Avalanche Association (CAA). 1995. Observation guidelines and recording standards for weather, snowpack and avalanches. Revelstoke, B.C., Canadian Avalanche Association.

Colbeck, S. C. 1987. A review of the metamorphism and classification of seasonal snow cover crystals. International Association of Hydrological Sciences Publication 162 (Symposium at Davos 1986 - Avalanche Formation, Movement and Effects), 3-34.

Colbeck, S. C. 1988. On the micrometeorology of surface hoar growth on snow in mountainous areas. Boundary-Layer Meteorol., 44 (1-2), 1-12.

Colbeck, S. C. 1991. The layered character of snow covers. Rev. Geophys., 29(1), 81-96.

Colbeck, S. C. and 7 others. 1990. The international classification for seasonal snow on the ground. Wallingford, Oxon, International Association of Scientific Hydrology. International Commission for Snow and Ice.

Davis, R. E., B. Jamieson, J. Hughes and C. Johnston. 1997. Observations on buried surface hoar - persistent failure planes for slab avalanches in British Columbia, Canada. In ISSW'96. International Snow Science Workshop, 6-10 October 1996, Banff, Alberta. Proceedings. Revelstoke, B.C., Canadian Avalanche Association, 81-85.

Davis, R. E., B. Jamieson and C. D. Johnston. 1998. Observations on buried surface hoar in British Columbia, Canada - section plane analysis of layer evolution. In ISSW'98. International Snow Science Workshop, 27 September -1 October 1998, Sunriver, Oregon. Proceedings. Seattle, WA, Washington State Department of Transportation, 86-92.

DenHartog, S. L. 1982. Firn quake (a rare and poorly explained phenomenon). Cold Reg. Sci. Technol., 6, 173-74.

Föhn, P. M. B. 1987. The "Rutschblock" as a practical tool for slope stability evaluation. International Association of Hydrological Sciences Publication 162 (Symposium at Davos 1986 - Avalanche Formation, Movement and Effects), 223-228.

Föhn, P. M. B. 1993. Characteristics of weak snow layers or interfaces. In Armstrong, R., ed. ISSW'92. A merging of theory and practice. International Snow Science Workshop, 4-8 October 1992, Breckenridge, Colorado. Proceedings. Denver, CO, Avalanche Information Center, 160-170.

Fukuzawa, T. and H. Narita. 1993. An experimental study on mechanical behaviour of a depth hoar under shear stress. In Armstrong, R., ed. ISSW'92. A merging of theory and practice. International Snow Science Workshop, 4-8 October 1992, Breckenridge, Colorado. Proceedings. Denver, CO, Avalanche Information Center, 171-175.

Good, W. and G. Krüsi. 1993. Micro- and macro-analyses of stratigraphic snow profiles. In Armstrong, R., ed. ISSW'92. A merging of theory and practice. International Snow Science Workshop, 4-8 October 1992, Breckenridge, Colorado. Proceedings. Denver, CO, Avalanche Information Center, 1-9.

Good,W., G. Krüsi, J. von Niederhäusern and A. Roth. 1991. Preparation and analysis of high contrast stratigraphic profiles. In Brugnot, G., E. brun, H.
Gubler, H. Norem and L. Reynaud, eds. Symposium de Chamonix CISAIKAR. Les apports de la recherche scientifique à la neige, glace et avalanches, 4-8 juin 1991, Chamonix, France. Comptes rendus. Grenoble, Association Nationale pour l'Étude de la Neige et des Avalanches (ANENA), 40-45.

Hachikubo, A. and E. Akitaya. 1997a. Effect of wind on surface hoar growth on snow. 7. Geophys. Res. 102(D4) 4367-4373.

Hachikubo, A. and E. Akitaya. 1997b. Surface hoar growing for several days. In ISSW'96. International Snow Science Workshop, 6-10 October 1996, Banff, Alberta. Proceedings. Revelstoke, B.C., Canadian Avalanche Association, 86-89.

Hachikubo, A. and E. Akitaya. 1998. Daytime preservation of surface-hoar crystals. Ann. Glaciol., 26, 22-26.

Hachikubo, A., T. Fukuzawa and E. Akitava. 1994. Formation rate of surface hoar crystals under various wind velocities. In ISSW'94. International Snow Science Workshop, 30 October-3 November 1994, Snowbird, Utah. Proceedings. Snowbird, UT, P.O. Box 49, 132-137.

Jamieson, J. B. 1995. Avalanche prediction for persistent snow slabs. (Ph.D. thesis, University of Calgary.)

Jamieson, J. B. and C. D. Johnston. 1992. Snowpack characteristics associated with avalanche accidents. Can. Geotech. J., 29(5), 862-866.

Jamieson, J. B. and C. D. Johnston. 1993. Experience with rutschblocks. In Armstrong, R., ed. ISSW'92. A merging of theory and practice. International Snow Science Workshop, 4-8 October 1992, Breckenridge, Colorado. Proceedings. Denver, CO, Avalanche Information Center, 150-159.

Jamieson, J. B. and C. D. Johnston. 1994. Monitoring a shear frame stability index and skier-triggered slab avalanches involving persistent snowpack weaknesses In ISWW'94. International Snow Science Workshop, 30 October-3 November 1994, Snowbird, Utah. Proceedings. Snowbird, UT, P.O. Box 49, 14-21.

Jamieson, J. B. and C. D. Johnston. 1997. The compression test for snow stability. In ISSW'96. International Snow Science Workshop, 6-10 October 1996, Banff, Alberta. Proceedings. Revelstoke, B.C., Canadian Avalanche Association, 118-125.

Jamieson, J. B. and C. D. Johnston. 1998. Snowpack factors associated with strength changes of buried surface hoar layers. In ISSW'98. International Snow Science Workshop, 27 September-1 October 1998, Sunriver, Oregon. Proceedings. Seattle, WA, Washington State Department of Transportation, 74-85.

Kobayashi, T. 1961. The growth of snow crystals at low supersaturations. Philos. Mag., 6(71), 1363-1370.

Lang, R. M., B. R. Leo and R. L. Brown. 1984. Observations on the growth process and strength characteristics of surface hoar. In ISSW'84. A merging of theory and practice. International Snow Science Workshop, 24-27 October 1984, Aspen, Colorado. Proceedings. Aspen, CO, ISSW Workshop Committee, 188-195.

Mellor, M. 1968. Avalanches. CRREL Monogr. III-A3d.

Neave, H. R. and P. L. Worthington. 1988. Distribution-free tests. London, Unwin Hyman Ltd.

Perla, R. 1982. Preparation of section planes in snow specimens. F. Glaciol., 28(98), 199-204.

Perla, R. and T. M. H. Beck. 1983. Experience with shear frames. F. Glaciol., 29(103), 485-491.

Roch, A. 1966. Les variations de la résistance de la neige. International Association of Scientific Hydrology Publication 69 (Symposium at Davos 1965 Scientific Aspects of Snow and Ice Avalanches), 86-99.

Schweizer, J., J. B. Jamieson and D. Skjonsberg. 1998. Avalanche forecasting for transportation corridor and backcountry in Glacier National Park (BC, Canada). In Hestnes, E., ed. Proceedings of the Anniversary Conference 25 Years of Snow Avalanche Research, Voss, 12-16 May 1998. Oslo, Norwegian Geotechnical Institute, 238-244. (NGI Publication 203.)

Shapiro, L. H., J. B. Johnson, M. Sturm and G. L. Blaisdell. 1997. Snow mechanics: review of the state of knowledge and applications. CRREL Rep. 97-3.

Sommerfeld, R. A. 1984. Instructions for using the $250 \mathrm{~cm}^{2}$ shear frame to evaluate the strength of a buried snow surface. U.S. For. Serv. Res. Note RM-446, 1-6. 